\title{
Rapid 3D microwave printing of continuous carbon fiber reinforced plastics
}

\author{
Nanya Li*, Guido Link, John Jelonnek \\ Institute for Pulsed Power and Microwave Technology, Karlsruhe Institute of Technology, 76344 Eggenstein-Leopoldshafen, Germany \\ Submitted by S. K. Ong ${ }^{(1)}$, Singapore
}

Keywords:

Manufacturing process

Composite

Additive manufacturing

\begin{abstract}
A B S T R A C T
Using microwave heating in 3D printing of continuous carbon fiber reinforced plastic (CCFRP) instead of the traditional resistive heating constitutes a new approach for the additive production of high performance composite components. Without the intrinsic slow speed and contact needed heat transfer disadvantages, the instantaneous and volumetric heating benefits of microwave allows the fabrication of composites at higher speed. This paper presents the 3D microwave printing technology for CCFRP and investigates the mechanical properties of the tensile specimens that have been printed with different speeds. The printing process and mechanical properties of printed specimens are investigated and discussed.
\end{abstract}

\section{Introduction}

Three dimensional (3D) printing, also known as additive manufactur ing, has been developed for more than 30 years for potential application in aerospace, automotive and medical treatment [1]. Benefitted from the computer aided design, numerical and automatic control, the 3D print ing becomes a burgeoning method and may lead to a revolution in the manufacturing industry [2].

The 3D printing of carbon fiber reinforced thermoplastic com posite components using the fused filament fabrication method has been freed from the limitations of classic forming tools [3] and com plicated multi steps preparation. Additionally, the intense manual labor, expensive fabrication equipment (tooling and autoclaves) and material waste are eliminated from the manufacturing process. The combination of 3D printing technology with continuous carbon fiber reinforcements instead of polymer resin or short carbon fiber rein forced thermoplastics [4] is offering a significantly higher perfor mance and strength to weight ratio of the printed composite parts [5].

The challenge of the current state of the art of the printing tech nologies is the slow printing speed of continuous carbon fiber rein forced plastics (CCFRP). Markforged published the Mark series 3D printers; the printing speed during fabrication of continuous fiber reinforced polymer parts is about $7 \mathrm{~mm} / \mathrm{s}$, which is much lower than the speed used for plastic applications [6]. Similarly, pure plastic part printing has a speed of $18 \mathrm{~mm} / \mathrm{s}$, but the printing speed of CCFRP is only $5 \mathrm{~mm} / \mathrm{s}$ [7]. University College Dublin and Skolkovo innovation center have developed 3D printing methods of CCFRP at a maximum speed of $10 \mathrm{~mm} / \mathrm{s}[8,9]$, which is the highest speed reported

\footnotetext{
* Corresponding author.

E-mail address: nanya.li@kit.edu (N. Li).
}

currently. Fundamentally, the above mentioned challenge is caused by the intrinsically contact needed and slow heat conduction from the conventional heating nozzle to the continuous carbon fiber rein forced thermoplastic filaments. As known, laser, infrared or ultravio let heating sources can only heat the surface of CCFRP and transfer the heat to the core slowly. Therefore, current 3D printing methods of high performance fiber reinforced composites address the bottle neck of slow printing speed.

This paper proposes a high speed 3D microwave printing technol ogy of continuous carbon fiber reinforced thermoplastics. Microwaves (frequencies between $300 \mathrm{MHz}$ and $300 \mathrm{GHz}$ ) can penetrate composite materials without contact and provide the benefits of instantaneous, selective, volumetric and energy saving heating. The microwave heat ing rate, forward power and temperature variation during the printing process are researched. The tensile strengths of the specimens printed with different speeds are compared and discussed.

\section{3D microwave printing process}

The pre prepared continuous carbon fiber reinforced thermoplas tic filament firstly goes through an elaborated single mode coaxial resonant applicator and is heated inside, as shown in Fig. 1. The microwave is transferred into the applicator from the coupling port and transformed into TEM (transverse electric and magnetic field) wave in the applicator. The magnetic field of the TEM wave stimu lates induced currents in each carbon fiber and generates volumetri cally Joule heating (detailed information in Section 4). With the advantage of selective heating, only the CCFRP filaments are rapidly heated; the applicator and surrounding mediums remain at room temperature. Next, the microwave heated filaments will be dragged out continuously by the traction force that is generated when the fila ments adhere to the printing platform. 


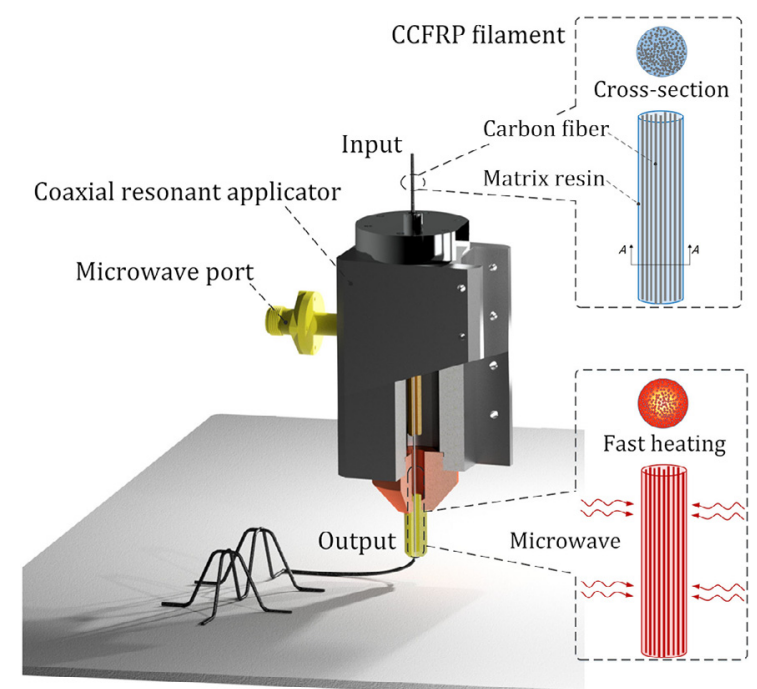

Fig. 1. Schematic diagram of the 3D microwave printing process of continuous carbon fiber reinforced thermoplastic composites.

\subsection{Materials}

Polyacrylonitrile based continuous carbon fibers of TORAY Tor ayca $1 \mathrm{~K}$ 66tex HT T300 was explored as the reinforcement and 910 polyamide filament (melting temperature: $190-255^{\circ} \mathrm{C}$ ) from Taul man was used as the matrix resin. Meanwhile, PA845 polyamide siz ing agent (Michelman, Inc.) was applied during the impregnation process of CCFRP filaments to enhance the interfacial strength between the fiber and the matrix. Continuous T300 carbon fiber rein forced polyamide filaments were prepared from the self developed impregnation system.

\subsection{D microwave printer Serpens}

The first prototype of a 3D microwave printer SERPENS (Super Effi cient and Rapid Printing by Electromagnetic heating Necessitated Sys tem) is shown in Fig. 2(a). The SERPENS is equipped a small size single mode coaxial microwave resonant applicator, infrared thermal camera, feeding motor, filament spool and control board. The applica tor was integrated in an upgraded three axis numerical control machine and links with a $300 \mathrm{~W}, 2.4$ to $2.5 \mathrm{GHz}$ solid state microwave power amplifier. A prediction model based control system of the 3D microwave printing temperature was developed to adjust the micro wave power during the printing process and eliminate the control delay in traditional proportional integral derivative (PID) process [10].
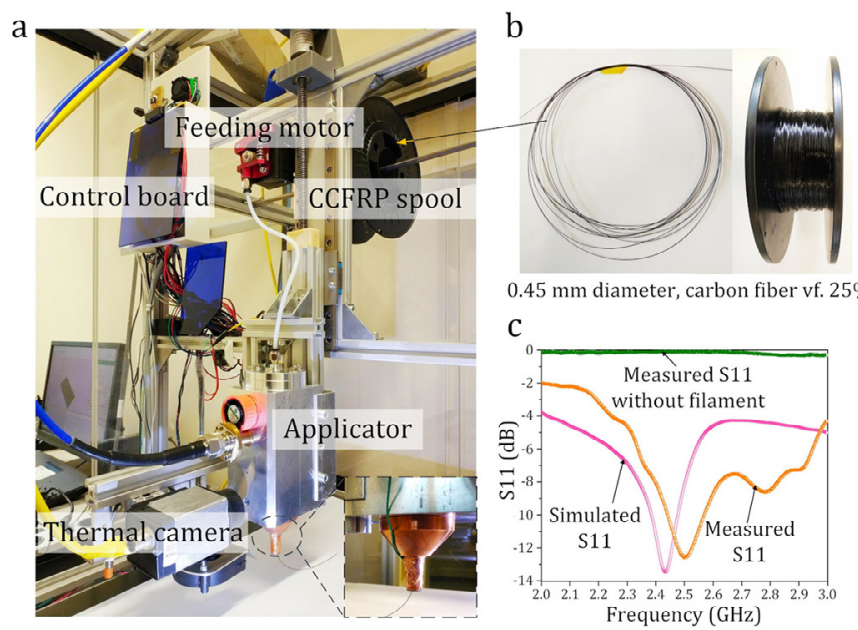

$0.45 \mathrm{~mm}$ diameter, carbon fiber vf. $25 \%$ $\mathrm{C}$

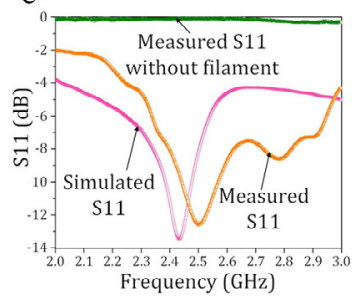

Fig. 2. (a) 3D microwave printer SERPENS, (b) impregnated CCFRP filaments, (c) comparison of the simulated and measured S11 of the microwave applicator with or without CCFRP filament.
A FLIR infrared thermal camera was applied to measure the tempera ture of the CCFRP filament inside the cavity. The pre prepared fila ments have a diameter of about $0.45 \mathrm{~mm}$, and the fiber volume content is about 25\%, as shown in Fig. 2(b). The S11 parameter repre sents the amount of power that is reflected from the microwave port, and is known as the reflection coefficient. As the continuous carbon fibers are drawn into the applicator as an inner conductor of the coax ial resonator, the microwave cannot couple with the applicator with out the CCFRP filaments and results in a total reflection, as shown in Fig. 2(c). The simulated result is similar to the measured result when the filament is inside the cavity, both of which have at least $-13 \mathrm{~dB}$ reflection coefficient in the region around 2.4 to $2.5 \mathrm{GHz}$, and indicates that the high efficiency resonant applicator has only about $5 \%$ power reflection. An Anritsu ML2488B power meter and Microlab CK $19 \mathrm{~N}$ microwave directional coupler have been used to measure the forward microwave power. An Olympus BX60M microscope was utilized to investigate the cross section of the printed specimens.

\section{Result and discussion}

The microwave heating mechanism of CCFRP is studied and shown in Fig. 3. The electric and magnetic fields inside the applicator are simulated using COMSOL to research which field has the main contribution to the heating process. The physical and electrical parameters are taken from the material library. As illustrated in Fig. 3 (a), the electric field has the highest intensity on the microwave port, the connection area of the large and the small cavity, and the output.

According to the Maxwell electromagnetic theory, an area with a high electric intensity corresponding to a low magnetic field. Thus, except the microwave coupling port, the magnetic field is concen trated in the small cavity that close to the output, as shown in Fig. 3 (b). The temperature distribution of the entire cavity within $3 \mathrm{~s}$ microwave radiation is shown in Fig. 3(c). The well designed imped ance of the cavities prompts a heating area near the output, and P1 to P6 probe points are marked along the CCFRP filament (shown in Fig. 3(c)) to measure the energy density and heating temperature. It can be observed that the microwave heating temperature of the CCFRP filament is in accordance with the variation of the magnetic field. For the coaxial resonator, the TEM mode is stimulated and the direction of the magnetic field ( $\mathrm{H}$ field) is vertical to the direction of propagation but circular around the filament, as illustrated in Fig. 3

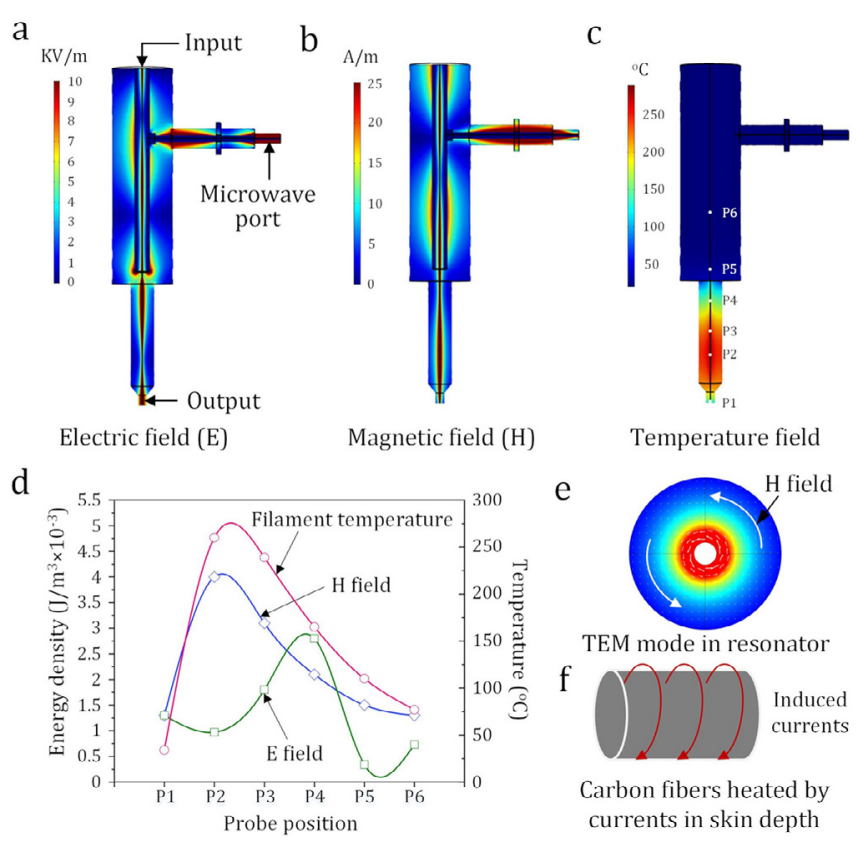

Fig. 3. (a), (b) and (c) Simulation results of electric, magnetic and temperature fields of the coaxial resonant applicator, (d) comparison of the energy density and temperature value of different probe points, (e) TEM mode stimulated in the resonator, (f) carbon fiber heated by induced currents. 
(e). The strong induced currents are generated on the surface (skin depth) of the each carbon fiber and become Joule heat, as shown in Fig. 3(f). According to the Joule heating of induced currents and skin depth theories, the skin depth of the TORAY T300 carbon fiber (elec tric resistivity: $1.6 \times 10^{-3} \Omega \mathrm{cm}$ ) under $2.45 \mathrm{GHz}$ microwave is about $0.04 \mu \mathrm{m}$, which will induce a strong heating in each carbon fiber (diameter is about $10 \mu \mathrm{m}$ ).

To increase the $Q$ factor (quality factor of the cavity) and prevent leakage of microwave from the applicator, a shortcut between the fila ment and the cavity should be applied in the output area. In our experi ments, the contact of the conductive carbon fiber reinforced filaments and the metal nozzle can achieve a shortcut during the printing process. The experiment results demonstrated that the heating temperature is influenced by the position of the filament and metal nozzle. At about $9 \mathrm{~W}$ and $16 \mathrm{~W}$ microwave power (measured forward power to the applicator), the filament shows a rapid temperature increase and a slight power decrease when a contact status has been established. As the shortcut of the cavity enhances the resonant TEM mode and reduces the leakage, the CCFRP filament is heated rapidly, as shown in Fig. 4. The increased $\mathrm{Q}$ factor reduces the microwave power that is needed. Evi dently, the nozzle increases the temperature due to the heat transfer from the filament, as illustrated in the yellow curve in Fig. 4. When the filament heats up, the nozzle temperature increases rapidly.

To investigate the relationship between the printing speed and the mechanical properties of the printed specimens, the tensile speci mens are manufactured, as shown in Fig. 5(a). The continuous carbon fibers are paved along the load transmission paths and printed layer by layer to form a $1 \mathrm{~mm}$ thickness part; each layer has a $0.15 \mathrm{~mm}$ height approximately. The printed filament has been compressed between the nozzle and the platform. The dimension and test param eters reference the ASTM D638 03 tensile testing standard. In Fig. 5 (b), the microwave heating rate of a static filament is measured under different power levels before the printing process to conduct a self test. The measurement results show that the heating temperature has an instantaneous response to the microwave power. The highest heating rate is about $62.5^{\circ} \mathrm{C} / \mathrm{s}$ under $18 \mathrm{~W}$ power. This means the temperature of the continuous carbon fiber reinforced polyamide fil ament can rise up to $200^{\circ} \mathrm{C}$ in less than $3 \mathrm{~s}$. The heating rate decreases to $12^{\circ} \mathrm{C} / \mathrm{s}$ at $3 \mathrm{~W}$ power. However, it is still higher than the $2{ }^{\circ} \mathrm{C} / \mathrm{s}$ heating rate of a traditional resistive heating nozzle.

During the printing process of the tensile specimens, the measured microwave power and printing speed are shown in Fig. 5(c). The straight printing path has the direction vectors in one direction and can achieve the highest printing speed. However, a low speed should be applied at the turning corners to ensure the filament can bond to the printing platform. Therefore, the microwave power should be con trolled precisely to follow the variation of the speed, and a prediction model based temperature control method was employed to control the power [10]. The experiment results demonstrate that the micro wave power is controlled by tracking the printing speed, and the straight printing paths have a higher speed of $50 \mathrm{~mm} / \mathrm{s}$, while the turn ing corners are $10 \mathrm{~mm} / \mathrm{s}$. As shown in Fig. 5(c), the microwave power has a slight decrease due to the decline of the working efficiency of the

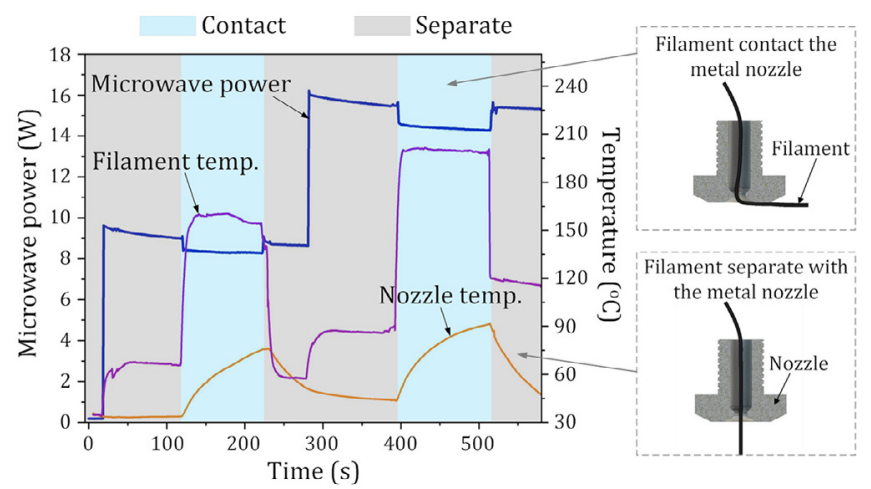

Fig. 4. Measured microwave power and heating temperature of the CCFRP filament under contact and separate conditions.
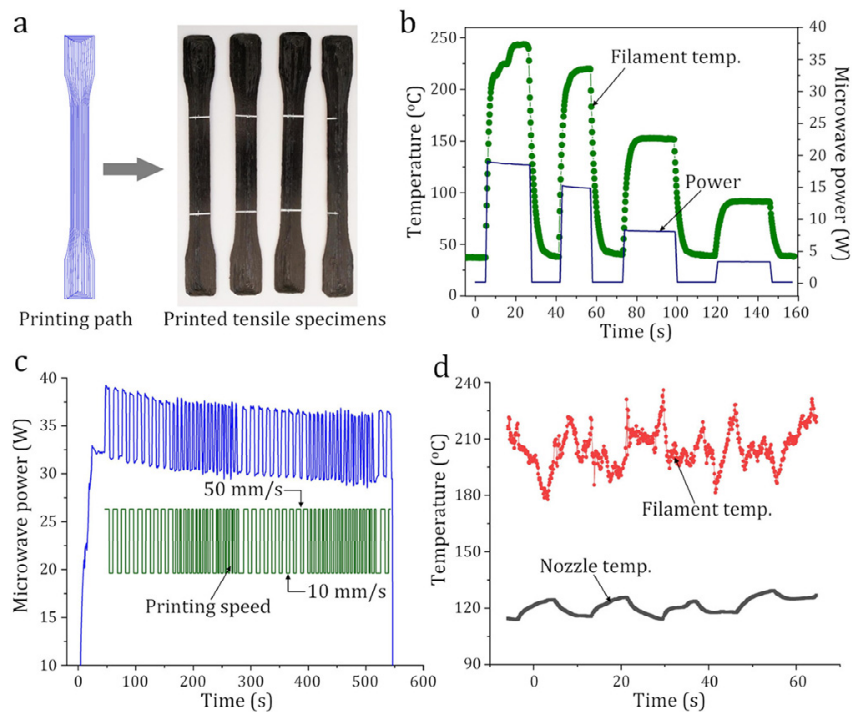

Fig. 5. (a) Printing path and the tensile specimens printed by SERPENS, (b) microwave heating rate of the filament, (c) the measured microwave power and printing speed, (d) variation of the filament and nozzle temperature during printing process.

solid state microwave power. The measured filament temperature during the printing of the tensile specimens has been analysed in Fig. 5(d). The temperature curve fluctuates around $180^{\circ} \mathrm{C}$ to $240{ }^{\circ} \mathrm{C}$ within one minute and the printing speed changes from $50 \mathrm{~mm} / \mathrm{s}$ to $10 \mathrm{~mm} / \mathrm{s}$ four times. The millisecond communication delay during the speed switching may cause an unstable heating temperature. Owing to the three axis numerical control machine used for printing, the applicator cannot rotate to different direction. Hence, the position of the filaments have to be shifted to adapt to the printing path, which may be another cause of the fluctuant temperature signal. The nozzle temperature is relatively stable and lower than the filament, as the strong heat convection is very beneficial to achieve fast cooling. As the heat transfer is time consuming, the variation of the nozzle tempera ture lags behind the filament temperature, but shows the exact four changes in speed. This would help to optimize the temperature control model in the on going research work.

As illustrated in Fig. 6(a), the tensile strengths of four sets of speci mens printed under four different speeds have been measured, i.e., 16 specimens. The average tensile strengths of the lowest $10 \mathrm{~mm} / \mathrm{s}$ speed is about $356 \mathrm{MPa}$. This result is better and higher than the specimens printed by other researchers by using lower speed and traditional resistive heating method [11, 12], which is $216 \mathrm{MPa}$ and $256 \mathrm{MPa}$ respectively. This may be due to the microwave selective heating of the carbon fibers, which can enhance the interfacial strength and achieve a better load transmission. In addition, the pre impregnated filaments help to achieve better quality and higher fiber volume con tent. With the high printing speed, the average strengths are about $358 \mathrm{MPa}, 313 \mathrm{MPa}$ and $347 \mathrm{MPa}$ for $20 \mathrm{~mm} / \mathrm{s}, 35 \mathrm{~mm} / \mathrm{s}$ and $50 \mathrm{~mm} / \mathrm{s}$, respectively. Due to some specimens were broken on the clamping areas, there is scattered data. Clearly, the high speed does not influence

a
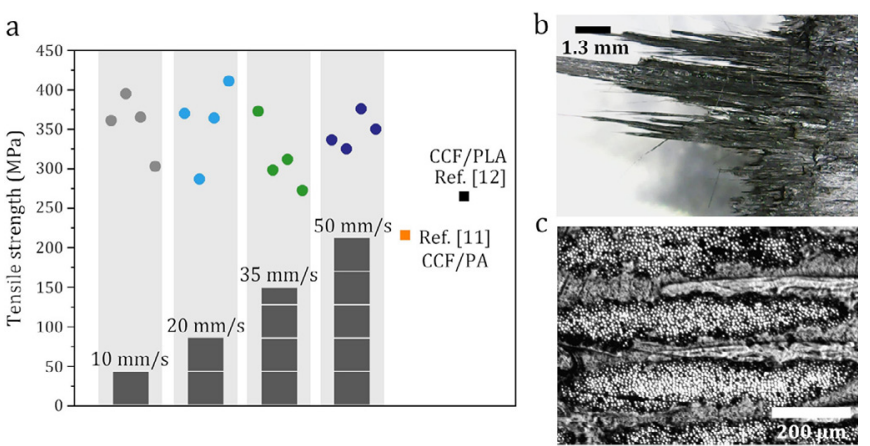

Fig. 6. (a) Tensile strength of the specimens with different speed, (b) broken area of the tensile specimens, (c) cross-section of the specimens. 


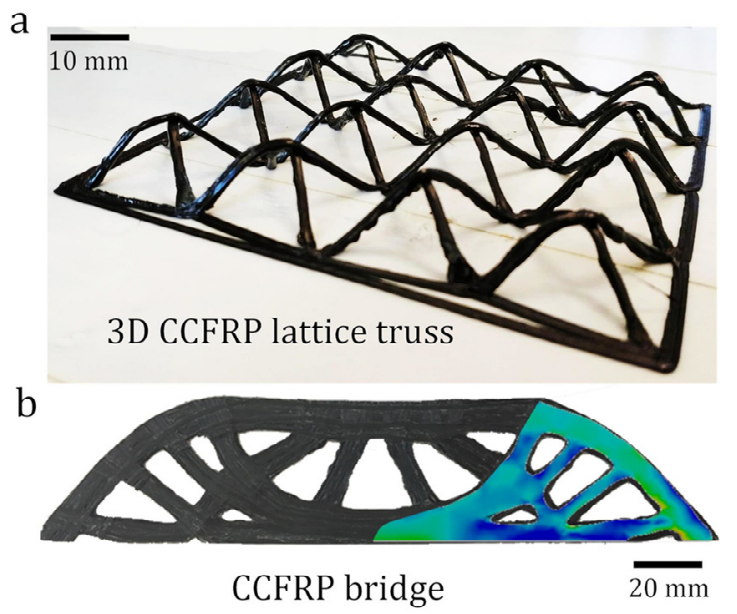

Fig. 7. (a) 3D CCFRP lattice truss structure printed by SERPENS, (b) microwave printed CCFRP bridge with high-speed.

the tensile strength of the 3D microwave printed parts and reduces the fabrication time tremendously. Compared with the CCF/PA $(7 \mathrm{~mm} / \mathrm{s}$ speed, Mark One printer) [11] and the CCF/PLA (1.7 mm/s speed) [12] parts printed in the references, the microwave printing at $50 \mathrm{~mm} / \mathrm{s}$ speed increased the tensile strength of about $61 \%$ and $36 \%$. The broken area of the specimens shows the burst of fibers in Fig. 6(b), which means the load has been transferred to the fibers through the matrix resin. The printed part also has a high compaction degree and com pressed the fibers into strips, as shown in Fig. 6(c).

Fig. 7 shows some example CCFRP parts printed by SERPENS. Due to the benefits of microwave heating technology, the 3D CCFRP lattice truss structure and the bridge part can be manufactured with high speed. The free standing lattice truss was printed without supporting materials and has only carbon fibers as the skeletons to provide the strong mechanical property. The CCFRP bridges are analysed before the path planning with topological optimization and printed within only $15 \mathrm{~min}$, which is 5 times faster than the traditional method.

\section{Conclusion}

In this study, a novel 3D microwave printing process and system have been presented. By integrating microwave heating, the printing speed of CCFRP can be improved significantly compared to the state of the art research works based on traditional heating processes. The specimens manufactured by high speed microwave printing show higher tensile strengths than the current reports. The advantages of the 3D microwave printing can be concluded as:

a) High speed manufacturing; the rapid and non contact heating provides high printing speed of continuous carbon fiber reinforced thermoplastic composites. b) Energy saving and environment friendly; the microwave only heats the filament; the cavity and the surrounding medium remains at room temperature. The closed cavity prevents the emission of harmful gasses.

c) Possibility to enhance the interfacial strength; the microwave selective heating of carbon fibers can improve the bonding strength with the resin matrix based on the preliminary work of the authors.

In future, a research to further increase the printing speed and process precision are necessary. With the developed coaxial micro wave resonant applicator, printing system and procedure, more research will be performed at higher speed in other applications, such as 3D lattice truss, load bearing CCFRP composite structures and multifunctional components.

\section{Acknowledgement}

The authors would like to thank the support of Alexander von Humboldt Foundation as well as to the donor, the German Federal Ministry for Education and Research.

\section{References}

[1] Thompson MK, Moroni G, Vaneker T, Fadel G, Campbell RI, Gibson I, Bernard A, Schulz G, Graf P, Ahuja B, Martina F (2016) Design for Additive Manufacturing: Trends, Opportunities, Considerations, and Constraints. CIRP Annals 65:737-760.

[2] Wei C, Li L, Zhang X, Chueh YH (2018) 3D Printing of Multiple Metallic Materials via Modified Selective Laser Melting. CIRP Annals 67:245-248.

[3] Bourell D, Kruth JP, Leu M, Levy G, Rosen D, Beese AM, Clare A (2017) Materials for Additive Manufacturing. CIRP Annals 66(2):659-681.

[4] Heller BP, Smith DE, Jack DA (2019) Planar Deposition Flow Modeling of Fiber Filled Composites in Large Area Additive Manufacturing. Additive Manufacturing 25:227-238.

[5] Li N, Link G, Ting W, Ramopoulos V, Neumaier D, Hofele J, Walter M, Jelonnek J (2020) Path-designed 3D Printing for Topological Optimized Carbon Fiber Composite Structures. Composite Part B: Engineering 128:1-12.

[6] Blok LG, Longana ML, Yu H, Woods BK (2018) An Investigation into 3D Printing of Fibre Reinforced Thermoplastic Composites. Additive Manufacturing 22:176-186.

7] Ye W, Lin G, Wu W, Geng P, Hu X, Gao Z, Zhao J (2019) Separated 3D Printing of Continuous Carbon Fiber Reinforced Thermoplastic Polyimide. Composites Part A: Applied Science and Manufacturing 121:457-464.

[8] Azarov AV, Antonov FK, Golubev MV, Khaziev AR, Ushanov SA (2019) Composite 3D Printing for the Small Size Unmanned Aerial Vehicle Structure. Composites Part B: Engineering 169:157-163.

[9] Dickson AN, Dowling DP (2019) Enhancing the Bearing Strength of Woven Carbon Fibre Thermoplastic Composites Through Additive Manufacturing. Compos Struct 212:381-388.

[10] Li N, Link G, Jelonnek J (2020) 3D Microwave Printing Temperature Control of Continuous Carbon Fiber Reinforced Composites. Composite Science and Technology . https://doi.org/10.1016/j.compscitech 2019.107939.

[11] Dickson AN, Barry JN, McDonnell KA, Dowling DP (2017) Fabrication of Continuous Carbon, Glass and Kevlar Fibre Reinforced Polymer Composites using Additive Manufacturing. Additive Manufacturing 16:146-152.

[12] Tian X, Liu T, Wang Q, Dilmurat A, Li D, Ziegmann G (2017) Recycling and Remanufacturing of 3D Printed Continuous Carbon Fiber Reinforced PLA Composites. Journal of Cleaner Production 142:1609-1618. 
Karlsruher Institut für Technologie

\section{Repository KITopen}

Dies ist ein Postprint/begutachtetes Manuskript.

Empfohlene Zitierung:

Li, N.; Link, G.; Jelonnek, J.

Rapid 3D microwave printing of continuous carbon fiber reinforced plastics.

2020. CIRP annals, manufacturing technology, 69

doi: $10.554 / I R / 1000119813$

Zitierung der Originalveröffentlichung:

Li, N.; Link, G.; Jelonnek, J.

Rapid 3D microwave printing of continuous carbon fiber reinforced plastics.

2020. CIRP annals, manufacturing technology, 69 (1), 221-224.

doi:10.1016/j.cirp.2020.04.057

Lizenzinformationen: CC BY-NC-ND 4.0 